\title{
Genetic parameters for fertility traits assessed in herds divergent in milk energy output in Holstein-Friesian, Brown Swiss, and Simmental cattle
}

\author{
M. Martinez-Castillero, ${ }^{1}$ H. Toledo-Alvarado, ${ }^{2}$ S. Pegolo, ${ }^{1 *}$ A. I. Vazquez,, 3 G. de los Campos,,${ }^{3,4,5}$ L. Varona, ${ }^{6}$ \\ R. Finocchiaro, ${ }^{7}$ G. Bittante, ${ }^{1}$ and A. Cecchinato ${ }^{1}$ \\ ${ }^{1}$ Department of Agronomy, Food, Natural Resources, Animals and Environment (DAFNAE), University of Padova, Viale dell' Università 16, 35020, \\ Legnaro PD, Italy \\ ${ }^{2}$ Department of Genetics and Biostatistics, School of Veterinary Medicine and Zootechnics, National Autonomous University of Mexico, \\ Ciudad Universitaria, 0451, Mexico City, México \\ ${ }^{3}$ Department of Epidemiology and Biostatistics, Michigan State University, 909 Fee Road, East Lansing 48824 \\ ${ }^{4}$ Institute for Quantitative Health Science and Engineering, Michigan State University, 775 Woodlot Drive, East Lansing 48824 \\ ${ }^{5}$ Department of Statistics and Probability, Michigan State University, 619 Red Cellar Road, East Lansing 48824 \\ ${ }^{6}$ Unidad de Genética Cuantitativa y Mejora Animal, Instituto Agroalimentario de Aragón (IA2), Universidad de Zaragoza, Calle de Miguel Servet, \\ 177, 50013, Zaragoza, Zaragoza, Spain \\ ${ }^{7}$ Associazione Nazionale Allevatori bovini della razza Frisona e Jersey Italiana (ANAFIJ), Via Bergamo 292, 26100 Cremona, Italy
}

\section{ABSTRACT}

In this study, we aimed to investigate differences in the genetics of fertility traits (heritability of traits and correlations between traits in divergent environments) in dairy cows of different production levels defined on the basis of the herd-average daily milk energy output (herd-dMEO). Data were obtained from Holstein-Friesian ( $\mathrm{n}=37,359$ for fertility traits, 381,334 for dMEO), Brown Swiss $(\mathrm{n}=79,638$ for fertility traits, 665,697 for dMEO), and Simmental cows $(n=63,048$ for fertility traits, 448,445 for dMEO) reared in northeastern Italy. Fertility traits under study were interval from calving to first service, interval from first service to conception, days open, calving interval, calving rate, and nonreturn rate at $\mathrm{d} 56$. We classified herds into low and high productivity based on the herd-average dMEO (inferred using mixed effects models). We estimated genetic parameters using Bayesian bivariate animal models, where expressions of a phenotype in the low and high dMEO herds were taken as being different-albeit correlated - traits. Fertility traits were more favorable in Simmental than in Holstein-Friesian cows, whereas for all traits, Holstein-Friesian had the highest estimates of intraherd heritability [ranging from 0.021 (0.006-0.038) to $0.126(0.10-0.15)$ ] and Simmental the lowest [ranging from $0.008(0.001-0.017)$ to $0.101(0.08-0.12)]$. The genetic correlations between fertility traits and dMEO were moderate and unfavorable, ranging, in absolute values, from $0.527(0.37-0.68)$ to $0.619(0.50-0.73)$ in Holstein-Friesian; from $0.339(0.20-0.47)$ to 0.556

Received May 21, 2020.

Accepted September 2, 2020.

*Corresponding author: sara.pegolo@unipd.it
(0.45-0.66) in Brown Swiss; and from 0.340 (0.10-0.60) to $0.475(0.33-0.61)$ in Simmental cattle. The only exception was the nonreturn rate at $\mathrm{d} 56$, which had weak genetic correlations with dMEO in all 3 breeds. The herd correlations between fertility and $\mathrm{dMEO}$ tended to be modest and favorable and the residual correlations modest and variable. The heritability of fertility traits tended to be greater in the low dMEO than in the high dMEO herds in the case of the Holstein-Friesians, but not in the case of the Brown Swiss or Simmentals. The additive genetic correlations between fertility traits in the low and high dMEO herds were always lower than $1[0.329(-0.17$ to 0.85$)$ to 0.934 (0.86 to 0.99$)]$ for all traits considered in all breeds. The correlation was particularly low for the threshold characters and the interval from first service to conception in HolsteinFriesian, suggesting that the relative performances of genotypes vary significantly between herds of different dMEO levels. Although there was large variability in the estimates, results might support making separate genetic evaluations of fertility in the different herd production groups. Our results also indicate that Simmental, a dual-purpose breed, has higher fertility and lower environmental sensitivity than Holstein-Friesian, with Brown Swiss being intermediate.

Key words: genotype by environment $(\mathrm{G} \times \mathrm{E})$, conception rate, calving interval, days open, milk yield and fertility

\section{INTRODUCTION}

Female fertility is one of the breeding objectives for dairy cattle worldwide (González-Recio and Alenda, 2005; Liu et al., 2008; Muuttoranta et al., 2019). Poor fertility negatively affects the longevity of the cows, is 
detrimental to productive performance, and has a negative effect overall on the profitability of the dairy farm (Miglior et al., 2017; Weigel et al., 2017).

Previous studies suggest that the relationship between production and fertility traits may be nonlinear and vary across herds, breeds, and cows within breeds (Windig et al., 2005; Bello et al., 2012). Dual-purpose breeds, such as Simmental, are less affected at the herd and cow levels than specialized breeds like HolsteinFriesian and Brown Swiss (Stocco et al., 2017; ToledoAlvarado et al., 2017). Moreover, selective breeding for high productivity can lead to negative energy balance early in lactation, which can result in reduced fertility when the recovery stage is not well managed (Pryce et al., 2004).

Reproductive performance can be affected by several factors, including management practices and cow-level factors such as genetics. However, the inclusion of missing and censored data, along with the low heritability of the traits, make genetic influence more difficult to measure (Hou et al., 2009).

Genotype and environmental conditions (e.g., diet, temperature, health) can interact in complex ways. In quantitative genetics, this is often dealt with by taking the expression of the same phenotype in 2 or more different production environments as being different but correlated traits (Falconer, 1960). Genetic correlations $<1$ are indicative of a reranking of the sires across production conditions and may require environmentspecific genetic evaluations to be carried out.

Herds can be classified on the basis of different descriptors, such as location (e.g., geographical region), dairy system (e.g., pasture, indoor traditional, indoor intensive), management practices (e.g., TMR, tied animals), or output (e.g., high or low productivity) (Haile-Mariam et al., 2008; Ismael et al., 2016). Several studies have investigated whether the same fertility trait expressed in herds with different production levels should be regarded as the same or different traits (Haile-Mariam et al., 2008; Strandberg et al., 2009), although only a few have classified herds using indicators of animal metabolic status (e.g., $\mathrm{NE}_{\mathrm{L}}$; Buttazzoni and Mao, 1989; Buaban et al., 2015).

Here, we classified herds using the herd-average daily milk energy output (herd-dMEO), which encompasses average daily milk yield (MY), milk composition, and $\mathrm{NE}_{\mathrm{L}}$, as an environmental descriptor to establish different production environments for the Holstein-Friesian (HO), Brown Swiss (BS), and Simmental (SM) cattle breeds. The objectives of our study were (1) to estimate the heritability and genetic correlations between dMEO and female fertility traits, and (2) to estimate the genetic correlations between fertility traits expressed in herds with different dMEO levels.

\section{MATERIALS AND METHODS}

\section{Data Set}

Records of the fertility and production traits of HO, BS, and SM cattle breeds were compiled for the study by the Breeders Federation of Alto Adige/Südtirol (Associazione Provinciale delle Organizzazioni Zootecniche Altoatesine/Vereinigung der Südtiroler Tierzuchtverbände, Bolzano/Bozen, Italy) in northeastern Italy. The original database before data editing consisted of 537,797 records of fertility traits $(120,955$ for HO, 234,877 for BS, 181,965 for SM), and 2,354,122 test-day records from production traits $\mathrm{MY}$, fat $(\mathbf{F P})$, protein (PP), and lactose (LP) percentages $(562,924$ for HO, 1,007,210 for BS, 783,988 for SM). From the original data set, $61.49 \%$ of herds included 1 breed, $30.55 \% 2$ breeds, and $7.96 \%$ all 3 breeds. Multi-breed herds were split into single-breed herds before statistical analysis. Fertility traits were both interval and categorical traits, as described in Tiezzi et al. (2011, 2012). Interval traits included the interval from calving to first service (iCF), the interval from first service to conception (iFC), days open (DO) (all right-censored), and calving interval (CInt). Categorical traits were calving rate (CR) and nonreturn rate at d 56 (NR56), coded as binary traits (0 and 1 ) and recorded at first insemination. For CR, 1 referred to a cow being pregnant, and for NR56, 1 referred to a cow with no second insemination registered and an observation interval $>56 \mathrm{~d}$.

The production traits used to compute dMEO were MY, FP, PP, and LP. We included only records from cows that calved between 2010 and 2018 from the first 3 parities, and discarded herds with fewer than 5 animals. The iCF, iFC, and DO records were considered censored if the cow's pregnancy was not confirmed. For $\mathrm{DO}$ and $\mathrm{iCF}$, we discarded records covering periods of $<20$ d.

We traced the pedigrees for each breed back 3 generations, which provided sufficient genetic information for estimation of genetic parameters (Yang and $\mathrm{Su}$, 2016), resulting in a total number of animals available in the pedigree after editing that ranged from 51,731 to 39,176 for $\mathrm{HO}$, from 78,895 to 55,476 for BS, and from 57,400 to 46,069 for SM. The total number of sires ranged from 1,685 to 1,896 for $\mathrm{HO}$, from 1,505 to 1,307 for BS, and from 747 to 810 for SM.

\section{Classification of Herds Using Herd-dMEO}

First, editing was performed to filter out potential outliers for each of the production traits (MY, FP, PP, and LP). A linear model was fitted including the fixed effects of (1) parity $(1,2,3)$, (2) DIM (12 classes in 
groups of $30 \mathrm{~d}$ each), and (3) year-season of calving, obtained by combining the year of calving (2010 to 2018) and season of calving (season $1=$ calving between April and September; season $2=$ calving between October and March). Records of test dates with residuals falling outside 3 standard deviations from the mean were removed from the data set.

The calculation of dMEO was then performed based on $\mathrm{NE}_{\mathrm{L}}(\mathrm{Mcal} / \mathrm{kg})$ in the milk produced, according to the following equation (NRC, 2001):

$$
\begin{aligned}
\mathrm{NE}_{\mathrm{L}}(\mathrm{Mcal} / \mathrm{kg}) & =0.0929 \times \mathrm{FP}+0.0547 \times \mathrm{PP} \\
& +0.0395 \times \mathrm{LP},
\end{aligned}
$$

where $0.0929,0.0547$, and 0.0395 are the individual heat of combustion coefficients for FP, PP, and LP, respectively.

We converted the $\mathrm{NE}_{\mathrm{L}}$ measures to megajoules per kilogram and multiplied this by the daily MY $(\mathrm{kg} / \mathrm{d})$ of each cow to obtain dMEO values expressed in megajoules per day. We then used dMEO to discriminate "environments" in terms of production level by fitting the following mixed model for each breed:

$$
\mathrm{dMEO}=\text { parity }+ \text { DIM }+ \text { yseason }+ \text { herd }+e,
$$

where parity, DIM, and yseason (year-season) were included as fixed effects (according to the previously defined classes), and herd as a random effect. The herd estimates were used to rank the herds from lowest to highest dMEO values. The median value was used to split the herds into 2 groups: low dMEO level (LL) and high dMEO level (HL). The median value was included in the LL group.

\section{Statistical Analyses}

Bivariate Genetic Models. For each breed separately, we used a sequence of bivariate animal models with dMEO and a fertility trait as phenotypes:

$$
\begin{aligned}
{\left[\begin{array}{l}
\mathbf{y}_{1} \\
\mathbf{y}_{2}
\end{array}\right]=} & {\left[\begin{array}{ll}
\mathbf{X}_{1} & 0 \\
0 & \mathbf{X}_{2}
\end{array}\right]\left[\begin{array}{l}
\mathbf{b}_{1} \\
\mathbf{b}_{2}
\end{array}\right]+\left[\begin{array}{ll}
\mathbf{W}_{11} & 0 \\
0 & \mathbf{W}_{12}
\end{array}\right]\left[\begin{array}{l}
\mathbf{h}_{1} \\
\mathbf{h}_{2}
\end{array}\right]+\left[\begin{array}{ll}
\mathbf{W}_{21} & 0 \\
0 & \mathbf{W}_{22}
\end{array}\right]\left[\begin{array}{l}
\mathbf{p}_{1} \\
\mathbf{p}_{2}
\end{array}\right] } \\
& +\left[\begin{array}{ll}
\mathbf{Z}_{1} & 0 \\
0 & \mathbf{Z}_{2}
\end{array}\right]\left[\begin{array}{l}
\mathbf{a}_{1} \\
\mathbf{a}_{2}
\end{array}\right]+\left[\begin{array}{l}
\mathbf{e}_{1} \\
\mathbf{e}_{2}
\end{array}\right],
\end{aligned}
$$

where $\mathbf{y}_{1}$ is the vector of the dMEO observations, and $\mathbf{y}_{2}$ corresponds to the phenotypic records of interval traits (iCF, iFC, DO, and CInt) or the liabilities of the categorical traits (CR and NR56); $\mathbf{X}_{1}$ and $\mathbf{X}_{2}$ are the incidence matrices for systematic effects: these included parity (3 classes) and year-season of calving (16 classes) for fertility traits, and DIM (12 classes) for dMEO; $\mathbf{W}_{11}, \mathbf{W}_{12}, \mathbf{W}_{21}, \mathbf{W}_{22}, \mathbf{Z}_{1}$, and $\mathbf{Z}_{2}$ are the incidence matrices of the random effects of herd, permanent environment, and additive genetic; $\mathbf{b}_{1}, \mathbf{b}_{2}, \mathbf{h}_{1}$, $\mathbf{h}_{2}, \mathbf{p}_{1}, \mathbf{p}_{2}, \mathbf{a}_{1}$, and $\mathbf{a}_{2}$ are the vectors of the systematic effects corresponding to each of the traits in the model, and those of the random effects; and $\mathbf{e}_{1}$ and $\mathbf{e}_{2}$ are the vectors of the residual effects. Random effects of herd, permanent environment, animal additive genetic, and residual were assumed to follow a multivariate normal distribution with mean 0 and variances $\mathbf{H} \otimes \mathbf{I}, \mathbf{P} \otimes \mathbf{I}$, $\mathbf{G} \otimes \mathbf{A}$, and $\mathbf{R} \otimes \mathbf{I}$, where

$$
\begin{gathered}
\mathbf{H}=\left[\begin{array}{cc}
\sigma_{\mathrm{herd} 1}^{2} & \sigma_{\mathrm{herd} 12} \\
\sigma_{\mathrm{herd} 21} & \sigma_{\mathrm{herd} 2}^{2}
\end{array}\right], \\
\mathbf{P}=\left[\begin{array}{cc}
\sigma_{\mathrm{pe} 1}^{2} & \sigma_{\mathrm{pe} 12} \\
\sigma_{\mathrm{pe} 21} & \sigma_{\mathrm{pe} 2}^{2}
\end{array}\right], \\
\mathbf{G}=\left[\begin{array}{cc}
\sigma_{\mathrm{a} 1}^{2} & \sigma_{\mathrm{a} 12} \\
\sigma_{\mathrm{a} 21} & \sigma_{\mathrm{a} 2}^{2}
\end{array}\right], \\
\text { and } \mathbf{R}=\left[\begin{array}{cc}
\sigma_{\mathrm{e} 1}^{2} & \sigma_{\mathrm{e} 12} \\
\sigma_{\mathrm{e} 21} & \sigma_{\mathrm{e} 2}^{2}
\end{array}\right]
\end{gathered}
$$

are the herd, permanent environment, genetic, and residual (co)variance matrices of the corresponding random effects, respectively. For binary traits, the threshold was set to 0 and the residual variance to 1 . In a first group of analyses, we fitted the above bivariate models within herd using data from all herds and without considering any classification of the herds based on dMEO.

Genetic Analyses Stratified by Herd-Average $d M E O$ Level. Next, we fitted bivariate models such as that just described but for each of the fertility traits. Thus, $\mathbf{y}_{1}$ and $\mathbf{y}_{2}$ corresponded to one of the interval traits or the liability of the binary traits expressed in the low- and high herd-dMEO herds, respectively. Because each herd and animal can fall into only one of the strata (either high or low), $\mathbf{H}, \mathbf{P}$, and $\mathbf{R}$ were diagonals (and $\mathbf{R}=\mathbf{I}$ for binary traits). However, we leveraged pedigree connections ( 1 sire had at least 2 daughters in each production environment) to estimate separate additive genetic variances and the genetic covariance between strata. 
Gibbs Sampler. We analyzed all models using a standard Bayesian approach, and estimated the marginal posterior distributions of unknown parameters by Gibbs sampler using the TM software, which is able to handle right-censored data using the technique of data augmentation (http://snp.toulouse.inra.fr/ alegarra/). For the bivariate models used to estimate the genetic parameters of dMEO and fertility traits, the total number of iterations was 500,000, with a burn-in of 20,000. For the bivariate models used for the genetic analyses stratified by the average herd-dMEO level, the total number of iterations was 800,000 , with a burn-in of 50,000 . We subsequently retained 1 out of every 10 successive samples in both cases. Post-Gibbs analyses and estimation of the lower and upper bounds of the $95 \%$ highest posterior probability density (HPD95) regions for heritabilities and correlations were carried out using the R software (R Core Team, 2018).

We calculated intraherd $(i h)$ heritability as $h_{i h}^{2}=\sigma_{a}^{2} /\left(\sigma_{a}^{2}+\sigma_{e}^{2}\right)$ and herd variance ratio $\left(h_{h}\right)$ as $h_{h}=\sigma_{h}^{2} /\left(\sigma_{a}^{2}+\sigma_{h}^{2}+\sigma_{e}^{2}\right)$, where $\sigma_{a}^{2}, \sigma_{e}^{2}$, and $\sigma_{h}^{2}$ are the additive genetic, residual, and herd variances, respectively. Estimates of correlation $\left(r_{a}\right.$, genetic, herd, permanent environment, and residual) were calculated as $r_{a}=\frac{\operatorname{cov}_{i}(x, y)}{\sigma_{i, x} \times \sigma_{i, y}}$, where $i$ refers to the genetic, herd, permanent environment, or residual correlation; $x$ and $y$ refer to the fertility trait expressed in the LL and HL herds; $\operatorname{cov}_{i}(x, y)$ is the covariance between the traits; and $\sigma_{i, x}$ and $\sigma_{i, y}$ are the respective standard deviations for the trait.

\section{RESULTS AND DISCUSSION}

\section{Differences Among Breeds and Between Herd-dMEO Classifications}

Descriptive statistics are presented in Table 1. The most extensive data set available was for BS ( $\mathrm{n}=79,638$ for fertility traits, 665,697 for dMEO), followed by SM ( $\mathrm{n}=63,048$ for fertility traits, 448,445 for dMEO), and HO cattle ( $\mathrm{n}=37,359$ for fertility traits, 381,334 for dMEO). The BS breed also accounted for the highest number of animals and herds (43,831 animals, 2,231 herds) compared with HO (23,639 animals, 1,318 herds) and SM (28,298 animals, 1,732 herds). However, the HO breed accounted for the highest number of sires available for analyses $(1,896)$ compared with BS $(1,505)$ and SM (810). The majority of sires and service bulls were from Italian, American, German, Austrian, and
Swiss herd books (Cecchinato et al., 2015). Artificial insemination was the common practice in the herds included in the study. The average value of censored records was $29.1 \%$ in $\mathrm{HO}, 27.8 \%$ in BS, and $21 \%$ in SM. The lower incidence of censored records in SM reflects the lower culling rate of dual-purpose breeds compared with specialized breeds (Table 1).

Average values for all fertility traits were more favorable in SM than HO (Table 1). The BS cows showed average fertility traits in between the other 2 breeds, but closer to HO than to SM, especially for iFC, CInt, CR, and NR56. In a survey in the same area, we analyzed in detail the fertility traits of HO, BS, and SM breeds, and also of the dual-purpose Alpine Grey cattle, according to 5 herd production levels (Toledo-Alvarado et al., 2017) defined by dMEO, and we found similar results (SM and Alpine Grey were much more fertile than $\mathrm{HO}$, and $\mathrm{BS}$ was slightly better than $\mathrm{HO}$ ). In a different herd management system; that is, the large, modern, intensive dairy farms of the plains, SM cows were also found to have better fertility than the HO and BS cows (Bittante et al., 2020). Selection for increasing MY and for the angularity of HO cows has resulted in a reduction of BCS (Hansen et al., 1999), which can be associated with higher susceptibility to infectious diseases and poor fertility (Roche et al., 2009). In contrast, dual-purpose cows, which generally have a higher BCS and that can mobilize some muscular tissue at the beginning of lactation, show better health and higher fertility than HO (Piccand et al., 2013). As expected, HO had the highest mean value of the indicator trait dMEO (83.8 MJ/d), although the values were similar for $\mathrm{BS}(73.6 \mathrm{MJ} / \mathrm{d})$ and $\mathrm{SM}(72.6 \mathrm{MJ} / \mathrm{d})$, which is mostly attributable to different MY (on average 3-4 $\mathrm{kg} / \mathrm{d}$ greater for $\mathrm{HO}$ than for BS and SM). This is a smaller difference in productivity than is often found in average MY measures reported in national databases, where differences in breeds often go hand in hand with differences in breeding area, altitude, dairy system, and farm size. An almost identical difference (HO having a corrected MY $3 \mathrm{~kg} / \mathrm{d}$ more than BS and SM) emerged from a within-farm comparison of multi-breed herds in a nearby province (Stocco et al., 2017), whereas a survey of intensive farms on the plains found a similar difference between $\mathrm{HO}$ and $\mathrm{BS}$, but a larger difference between $\mathrm{HO}$ and $\mathrm{SM}(+5 \mathrm{~kg} / \mathrm{d})$, after correcting $\mathrm{MY}$ for composition (Bittante et al., 2020). Expressed in relative terms (10-13\%), the difference between breeds was similar to that found in the present study.

To rank the herds and carry out the genetic analyses, we implemented a model including the season effect split into 2 levels. This was done because most of the farms were small and they were located in the mountainous 
Table 1. Descriptive statistics for fertility traits and milk energy output (dMEO, MJ/d) in Holstein-Friesian, Brown Swiss, and Simmental cattle

\begin{tabular}{|c|c|c|c|c|c|c|}
\hline Trait and breed & Records & Animals & Herds & Sires & $\begin{array}{l}\text { Mean }_{(\mathrm{SD})} \text { or } \\
\text { incidence }(\%)\end{array}$ & $\begin{array}{l}\text { Censored } \\
\text { records (\%) }\end{array}$ \\
\hline \multicolumn{7}{|c|}{ Calving-first service (iCF) } \\
\hline Simmental & 63,048 & 24,995 & 1,587 & 810 & 78 & 20.9 \\
\hline \multicolumn{7}{|c|}{ First service-conception (iFC) } \\
\hline Holstein-Friesian & 37,169 & 19,062 & 1,175 & 1,895 & $38_{(55)}$ & 29.5 \\
\hline \multicolumn{7}{|l|}{ Days open (DO) } \\
\hline Holstein-Friesian & 37,169 & 19,062 & 1,175 & 1,895 & $138_{(73)}$ & 28.8 \\
\hline Brown Swiss & 79,082 & 38,051 & 2,157 & 1,496 & $129_{(71)}$ & 27.5 \\
\hline Simmental & 62,858 & 24,942 & 1,586 & 810 & 115 & 20.9 \\
\hline \multicolumn{7}{|c|}{ Calving interval (CInt) } \\
\hline Holstein-Friesian & 26,805 & 14,608 & 1,074 & 1,685 & 423 & - \\
\hline Brown Swiss & 57,928 & 28,952 & 2,040 & 1,307 & 421 & - \\
\hline \multicolumn{7}{|c|}{ Nonreturn rate to $56 \mathrm{~d}$ (NR56) } \\
\hline Holstein-Friesian & 37,359 & 19,132 & 1,177 & 1,896 & $65.5 \%$ & \\
\hline Brown Swiss & 79,638 & 38,231 & 2,160 & 1,505 & $66.2 \%$ & \\
\hline Simmental & 63,048 & 24,995 & 1,587 & 810 & $70.4 \%$ & \\
\hline \multicolumn{7}{|c|}{ Milk energy output (dMEO) } \\
\hline Holstein-Friesian & 381,334 & 23,639 & 1,318 & 1,795 & $83.8_{(22.6)}$ & - \\
\hline Brown Swiss & 665,697 & 43,831 & 2,231 & 1,384 & 73.6 & - \\
\hline Simmental & 448,445 & 28,298 & 1,732 & 749 & $72.6(20.5)$ & - \\
\hline
\end{tabular}

areas of northern Italy; with 2 seasons, a possible major effect due to daylight length and barn temperature could be well absorbed. A preliminary analysis was also carried out including, or not, the cow effect (with or without the A matrix) and results showed a Spearman rank correlation of 0.99 between the 2 models and no difference in the ranking of the herds. Therefore, a cow effect was not included in the model used for the splitting herds. We considered the implementation of a reaction norm analysis. However, in a reaction norm analysis, the environment is considered a continuum and a range of environments is required (Schlichtig and Pigliucci, 1998). In this study, the number of records available did not allow a balanced distribution in each environment for an accurate estimation of genetic parameters.

Descriptive statistics for fertility traits based on the herd-average dMEO classification are reported in Table 2 . The average phenotypic difference in dMEO between LL and HL herds was similar for the 3 breeds (HO $+18.6 \mathrm{MJ} / \mathrm{d}$, BS +18.2 MJ/d, SM +18.3 MJ/d), and corresponded to a net energy of $6 \mathrm{~kg} / \mathrm{d}$ of MY (adjusted for the main environmental factors). In the survey carried out in the nearby province on mixed-breed herds (6 breeds), the average MY (adjusted for breed, parity, and lactation stage) of cows from farms above the median was $8.3 \mathrm{~kg} / \mathrm{d}$ (Stocco et al., 2017). In the survey carried out on single-breed farms in the same area as the present study but with herds classified into 5 productivity levels, the average herd mean MY ranged from $21 \mathrm{~kg} / \mathrm{d}$ for the lowest-yielding to $31 \mathrm{~kg} / \mathrm{d}$ for the highest-yielding herds of the HO breed, and from 16 to $26 \mathrm{~kg} / \mathrm{d}$ for herds of the BS and SM breeds (ToledoAlvarado et al., 2017). The survey of intensive farms on the plains found large variability in the herd mean MY (corrected for breed and main environmental factors), and averages of the 5 productivity levels ranged from 26 to $43 \mathrm{~kg} / \mathrm{d}$ (Bittante et al., 2020).

The LL and HL herd classes contained the same number of herds of each breed because the split was made along the median. However, there were more records, animals, and sires for HL herds than for LL herds for all traits and cattle breeds. This was because the HL herds are more often characterized by modern production systems and they are more intensively managed (loose housing, milking parlor, often use of TMR with moderate-high levels of concentrate) to achieve a higher average dMEO (HL) and, on average, have about twice the number of cows compared with LL herds. In contrast, LL herds are generally small and 


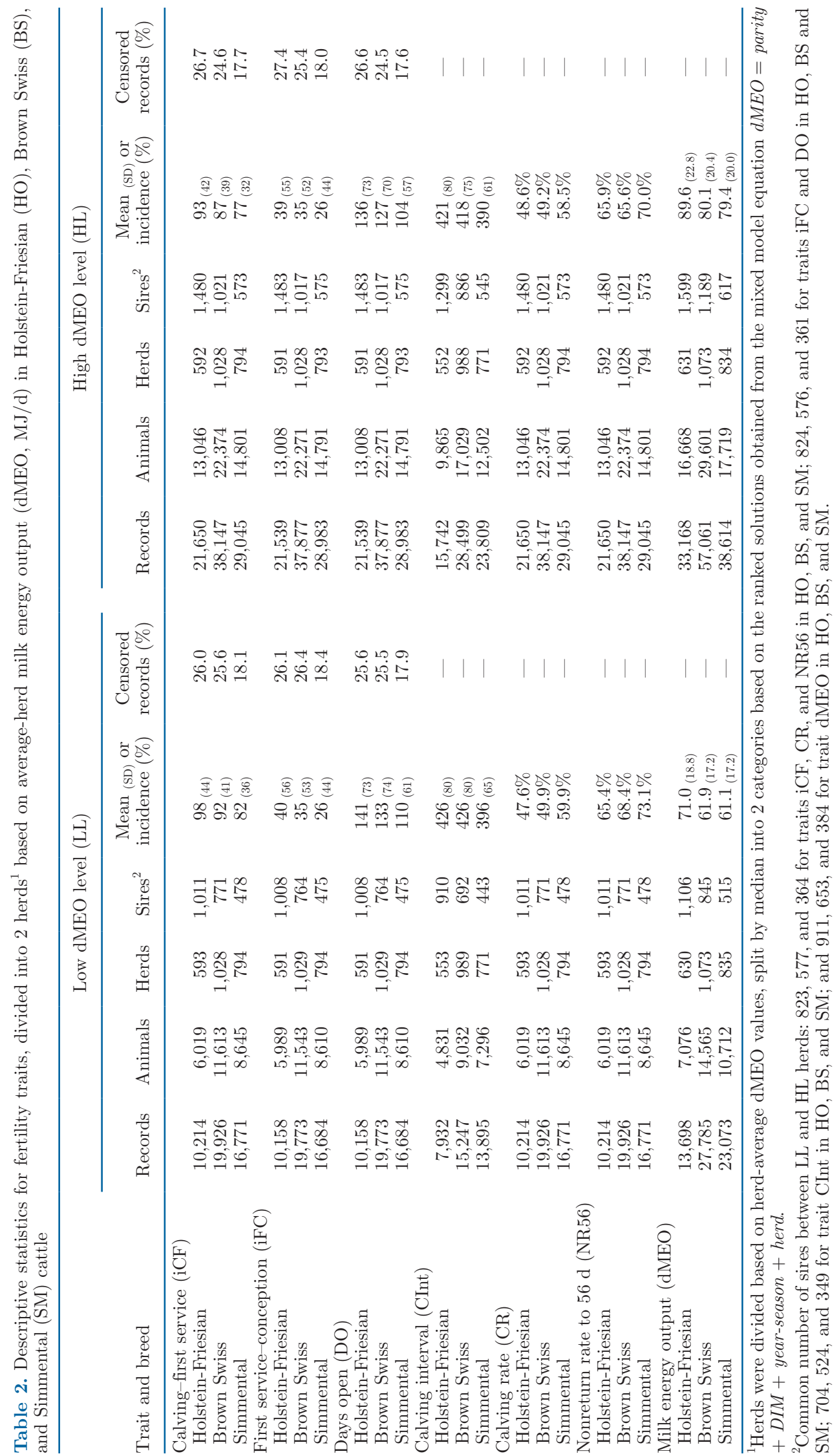


often characterized by a traditional production system (frequently tied animals, fed hay and a small proportion of compound feed). The incidence of censored records for fertility traits and dMEO was comparable between environments, suggesting no difference in the information available between the 2 herd production levels. In addition, we confirmed the lower incidence of censored records in the dual-purpose breeds (SM) compared with the specialized breeds (HO and BS; Table 2).

Overall, no substantial differences were detected in fertility traits among LL and HL herds, which suggested that herd production level did not have a large effect on the cows included in this study (Table 2). However, a longer $\mathrm{iCF}(+5 \mathrm{~d}$ on average) in the LL than in the HL herds was observed, whereas iFC did not differ (Table $2)$. Consequently, the longer DO ( $+5 \mathrm{~d}$ on average) and CInt $(+6 \mathrm{~d}$ on average) reflected the elongation of the first interval, not the second. The first insemination was delayed in the LL herd, but the service period was comparable in the 2 herd classes. These results are supported by the fact that the average $\mathrm{CR}$ was very similar in both tiers for all 3 breeds (Table 2). In the case of NR56, we observed a slightly higher average value in the HL than in the LL herds, but only for the BS and SM breeds.

The large survey in the same area comparing farms grouped into 5 productivity levels found an improvement in some fertility traits moving from the low- to the high-productivity herds (Toledo-Alvarado et al., 2017), a result that was attributed to better management and feeding of the latter herds. This favorable effect was evident for $\mathrm{iCF}, \mathrm{DO}$, and NR56, but much less evident for $\mathrm{iFC}$ and $\mathrm{CR}$, as in the present study. Moreover, the improvement was more evident for dual-purpose breeds than for $\mathrm{HO}$, with BS being intermediate. At the cow level; that is, in high- versus low-producing cows within herd, the opposite results were found: an increase in MY leads to a worsening of fertility traits (Toledo-Alvarado et al., 2017). Again, the effect was more evident in dual-purpose than in dairy breeds. At both the herd and the individual cow levels, the effect of dMEO on fertility tended to be curvilinear, with greater changes moving from low to medium dMEO than from medium to high dMEO. Excluding the 2 extreme dMEO groups of farms, the differences among the remaining 3 groups were more similar to the average fertility traits in the LL and HL herds. It is worth noting that in the survey of intensive dairy farms on the plains (Bittante et al., 2020), the relationship between herd average MY and conception rate was curvilinear and, in this case, the odds ratios for the first (very low MY farms) and second (low MY farms) groups of farms were not significantly different from that of the third (central) group (average MY $34 \mathrm{~kg} / \mathrm{d}$ ), whereas they were significantly higher for the fourth (high MY farms) and the fifth (very high MY farms). In the present study, we decided not to split the database into a larger number of productivity groups so that we would have a sufficient number of animals and farms in each group to estimate the genetic parameters.

\section{Genetic Parameters for Fertility Traits and dMEO}

The estimates of the additive genetic, herd, permanent environment, and residual variances, the intraherd heritabilities, and the herd variance ratio for the traits investigated are reported in Table 3. For all fertility traits and all breeds, the lowest variance component was due to the genetic effect, and the largest to the residual. The herd and permanent environment variances were intermediate, with the ratios among them varying according to trait and breed. The value of each variance component for every fertility trait was smaller for SM cows than for HO cows. The variance components for the BS cows were sometimes intermediate and sometimes more similar to the HO cows.

Estimates of intraherd heritability were low for all fertility traits (ranging from 0.01 to 0.13 ), the lowest values being for categorical traits $[0.008(0.001-0.017)$ to $0.025(0.009-0.043)]$, and the highest for interval traits $[0.030(0.02-0.04)$ to $0.126(0.10-0.15)]$. The highest heritability estimates among the 3 breeds were for HO for all fertility traits, which might be due to the data structure and intrinsic characteristics of the breed. In the case of the interval traits $(\mathrm{iCF}, \mathrm{iFC}, \mathrm{DO}$, and CInt), the mean heritability estimate for $\mathrm{HO}$ was always greater than the upper limit of the HPD95 of the SM estimate (Table 3). The heritability of the interval fertility traits of BS cows was within the HPD95 interval of the estimates of the other 2 breeds in the case of $\mathrm{iCF}$, was similar to $\mathrm{HO}$ and higher than $\mathrm{SM}$ for $\mathrm{iFC}$ and $\mathrm{DO}$, and similar to SM and lower than $\mathrm{HO}$ for CInt. In the case of the 2 categorical traits (CR and NR56), the heritability estimates had larger variability so that the mean value of each breed fell within the HPD95 interval of the others (Table 3). These results were in line with previously reported data for various breeds, including HO and BS (Tiezzi et al., 2012; Gredler and Schnyder, 2013; Tenghe et al., 2015).

The highest herd variance ratio estimates were obtained for the iCF trait in all 3 cattle breeds $[0.160$ (0.14-0.18) to $0.201(0.19-0.22)]$, and the lowest for iFC [0.050 (0.04-0.06) to $0.061(0.05-0.07)]$. The herd variance ratio estimates were higher than the heritability values, suggesting that nongenetic effects on fertility were stronger that the genetic effects. 
Martinez-Castillero et al.: FERTILITY, GENETIC RELATIONSHIPS, AND ENVIRONMENT

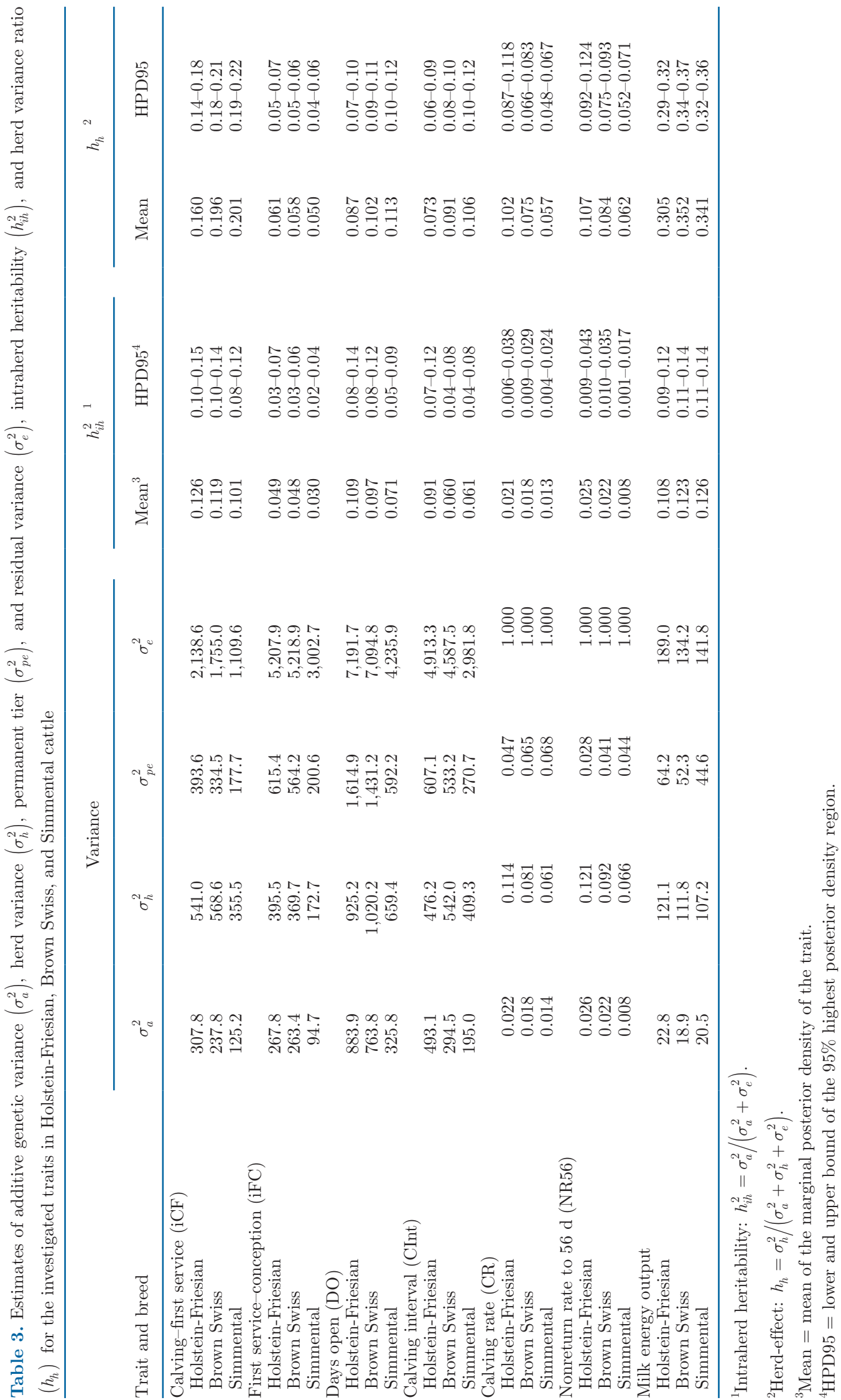


Among the different breeds, we observed that HO cows were affected by a mean herd variance ratio that was lower than the lowest HPD95 bound of the BS and SM breeds in the case of $\mathrm{iCF}$, and higher than the upper HPD95 interval of the HO cows (with BS intermediate) in the case of iFC (Table 3). These results could be interpreted as environmental conditions having a greater effect on the postpartum anestrus interval and the voluntary waiting period (iCF) in farms rearing BS and SM cows than in farms rearing HO cows. In contrast, the length of service period (iFC) was more variable within the different farms rearing $\mathrm{HO}$ than within those rearing SM cows. The estimates regarding DO and CInt are more affected by the variability in the first (iCF) than in the second (iFC) interval. Support for this interpretation is given by the fact that the 2 categorical fertility traits (CR and NR56) showed decreasing herd variance ratio, with greater changes moving from low to medium dMEO than from medium to high dMEO herds (Table 3 ).

For all cattle breeds, the highest variation in dMEO was due to both the residual $\left(134.2\right.$ to $\left.189.0 \mathrm{~kg}^{2} / \mathrm{d}^{2}\right)$ and the herd variance ratio $\left(107.2\right.$ to $\left.121.1 \mathrm{~kg}^{2} / \mathrm{d}^{2}\right)$; the lowest variation was due to the genetic effect (18.9 to $22.8 \mathrm{~kg}^{2} / \mathrm{d}^{2}$ ). Although all 3 breeds had low intraherd heritabilities for dMEO [ranging from 0.108 (0.09-0.12) to $0.126(0.11-0.14)]$, they were higher than those for fertility traits, except for $\mathrm{iCF}$, which had similar values. The mean heritability estimate of $\mathrm{HO}$ cows $[0.108$ (0.09-0.12)] was lower than the lower bound of the HPD95 interval of the heritability estimates of the BS and SM breeds. These values are comparable to those for MY ( $\sim 0.09-0.10$; data not shown) and lower than those for milk production traits $(\sim 0.21-0.31$ for $\mathrm{FP}, \sim 0.29-0.35$ for $\mathrm{PP}$, and $\sim 0.32-0.39$ for LP; data not shown), which suggests that MY had a greater influence on dMEO than the other traits included in the calculation. No heritability estimates for dMEO in the different breeds are reported in the scientific literature, although some estimates can be found for MY or corrected MY. A study in a nearby province obtained very similar results (intraherd heritability of daily MY ranging from 0.094 to 0.105 ), the value for the HO being slightly lower than for the BS and SM breeds (Cecchinato et al., 2015). Other authors have reported heritability values ranging from 0.09 (Danish Jersey) to 0.21 (Danish Holstein-Friesian; Poulsen et al., 2015).

The estimates of herd variance ratio for dMEO [ranging from $0.305(0.29-0.32)$ to $0.352(0.34-0.37)]$ were larger than those for fertility traits [ranging from 0.05 $(0.04-0.06)$ to $0.201(0.19-0.22)]$ and are due to the large variability in management and feeding practices across different dairy farms. These findings support us- ing the herd-average dMEO as the basis for classifying the different production levels to study fertility traits in dairy cattle. Moreover, the herd variance ratio for dMEO in HO cows $[0.305(0.29-0.32)]$ was lower than the lower bound of the HPD95 of the estimates for both Alpine breeds (BS: 0.34; SM: 0.32).

\section{Correlations Between dMEO and Fertility Traits}

Posterior means of the genetic, herd, and residual correlations obtained from the bivariate analyses between dMEO and fertility traits are shown in Table 4. Overall, for all fertility traits, the genetic correlations with $\mathrm{dMEO}$ were unfavorable for all breeds and relevant for all traits except for NR56. De Vries and Veerkamp (2000) found a within-herd relationship between a more substantial negative energy balance and both a delay in ovarian activity and changes in the milk fat percentage. Other studies have confirmed the existence of a relationship between fertility and postpartum changes in body condition and BW in lactating dairy cows (Carvalho et al., 2014).

Furthermore, for all fertility traits, excluding CR and NR56, the genetic correlations with dMEO were more unfavorable for HO than for SM cows (the mean value of the former breed was larger, in absolute value, than the upper bound of the HPD95 interval of the latter breed; Table 4). The values of the genetic correlations of BS cows were intermediate between the $\mathrm{HO}$ and SM breeds for $\mathrm{iCF}$ and CInt, and more similar to the SM mean values for $\mathrm{iFC}, \mathrm{DO}$, and $\mathrm{CR}$. The unfavorable genetic correlations between $\mathrm{dMEO}$ and fertility traits in the 3 breeds suggest that a higher dMEO results in delayed insemination, conception, and calving among the interval fertility traits, and a lower probability of conception among the categorical fertility traits. These results are consistent with previous data showing unfavorable genetic correlations between productivity and fertility (Philipsson and Lindhé, 2003; Patton et al., 2007; Bello et al., 2012).

Unlike the genetic correlations, the herd correlations for interval fertility traits (iCF, iFC, DO, and CInt) were all weak and favorable, with no clear pattern for the different breeds. Herd correlations for categorical traits (CR and NR56) were even weaker and more variable in sign, even though, in most cases, the HPD95 interval included zero. Herd correlations between dMEO and fertility traits suggest that cows belonging to herds with a higher dMEO tend to have shorter intervals for interval fertility traits, confirming previous findings that greater herd productivity can lead to higher fertility in cows. In contrast, a higher MY of individual cows within a herd leads to lower fertility (Toledo-Alvarado et al., 2017). 
Table 4. Estimates of additive genetic correlation $\left(r_{a}\right)$, herd correlation $\left(r_{h}\right)$, and residual correlation $\left(r_{e}\right)$ between fertility traits and the daily milk energy output (dMEO) in Holstein-Friesian, Brown Swiss, and Simmental cattle

\begin{tabular}{|c|c|c|c|}
\hline \multirow[b]{2}{*}{ Trait and breed } & \multicolumn{3}{|c|}{ Correlation $(r)$ with dMEO ${ }^{1}$} \\
\hline & $r_{a(\mathrm{HPD} 95)}$ & $r_{h(\mathrm{HPD} 95)}$ & $r_{e}(\mathrm{HPD} 95)$ \\
\hline \multicolumn{4}{|c|}{ Calving-first service (iCF) } \\
\hline Holstein-Friesian & $\mathbf{0 . 5 5 1} 1_{(0.43 ; 0.66)}$ & $\mathbf{- 0 . 1 5 8}(-0.23 ;-0.08)$ & $-0.031_{(-0.81 ; 0.29)}$ \\
\hline Brown Swiss & $\mathbf{0 . 4 3 9}(0.34 ; 0.54)$ & $-\mathbf{0 . 2 2 5}(-0.28 ;-0.17)$ & $0.061(-0.22 ; 0.38)$ \\
\hline Simmental & $\mathbf{0 . 3 4 5}(0.21 ; 0.49)$ & $\mathbf{- 0 . 1 7 1}(-0.23 ;-0.11)$ & $0.717_{(-0.40 ; 0.92)}$ \\
\hline \multicolumn{4}{|c|}{ First service-conception (iFC) } \\
\hline Holstein-Friesian & $\mathbf{0 . 5 2 7}(0.37 ; 0.68)$ & $\mathbf{- 0 . 1 0 7}(-0.20 ;-0.01)$ & $-0.088_{(-0.99 ; 0.63)}$ \\
\hline Brown Swiss & $\mathbf{0 . 3 3 9}(0.20 ; 0.47)$ & $\mathbf{- 0 . 1 3 1}(-0.20 ;-0.07)$ & $-0.075(-0.92 ; 0.45)$ \\
\hline Simmental & $\mathbf{0 . 2 0 8}(0.00 ; 0.40)$ & $-0.067_{(-0.14 ; 0.01)}$ & $0.026_{(-0.58 ; 0.52)}$ \\
\hline \multicolumn{4}{|l|}{ Days open (DO) } \\
\hline Holstein-Friesian & $\mathbf{0 . 6 1 0}(0.50 ; 0.72)$ & $\mathbf{- 0 . 1 7 7}(-0.26 ;-0.09)$ & $-0.265(-0.79 ; 0.31)$ \\
\hline Brown Swiss & $\mathbf{0 . 4 6 8}(0.37 ; 0.57)$ & $-\mathbf{0 . 2 4 1}(-0.30 ;-0.18)$ & $-0.155(-0.61 ; 0.24)$ \\
\hline Simmental & $\mathbf{0 . 3 5 0}(0.20 ; 0.49)$ & $\mathbf{- 0 . 1 6 3}(-0.23 ;-0.10)$ & $-0.382(-0.76 ; 0.15)$ \\
\hline \multicolumn{4}{|c|}{ Calving interval (CInt) } \\
\hline Holstein-Friesian & $\mathbf{0 . 6 1 9}(0.50 ; 0.73)$ & $\mathbf{- 0 . 2 2 8}(-0.32 ;-0.14)$ & $-0.520_{(-0.08 ; 0.99)}$ \\
\hline Brown Swiss & $\mathbf{0 . 5 5 6} \mathbf{6}_{(0.45 ; 0.66)}$ & $\mathbf{- 0 . 2 8 4}(-0.34 ;-0.23)$ & $0.076(-0.45 ; 0.68)$ \\
\hline Simmental & $\mathbf{0 . 4 7 5}(0.33 ; 0.61)$ & $\mathbf{- 0 . 2 4 0}(-0.30 ;-0.17)$ & $0.057(-0.10 ; 0.86)$ \\
\hline \multicolumn{4}{|l|}{ Calving rate $(\mathrm{CR})$} \\
\hline Holstein-Friesian & $\mathbf{- 0 . 5 7 9}(-0.76 ;-0.40)$ & $\mathbf{0 . 1 1 0}(0.02 ; 0.20)$ & $0.001_{(-0.16 ; 0.15)}$ \\
\hline Brown Swiss & $\mathbf{- 0 . 3 5 6}(-0.55 ;-0.17)$ & $0.047_{(-0.02 ; 0.11)}$ & $-0.023(-0.20 ; 0.17)$ \\
\hline Simmental & $-\mathbf{0 . 3 4 0}(-0.60 ;-0.10)$ & $0.011_{(-0.07 ; 0.10)}$ & $-0.045(-0.26 ; 0.20)$ \\
\hline \multicolumn{4}{|c|}{ Nonreturn rate to $56 \mathrm{~d}$ (NR56) } \\
\hline Holstein-Friesian & $-0.274(-0.58 ; 0.01)$ & $0.026_{(-0.07 ; 0.12)}$ & $-0.009_{(-0.15 ; 0.14)}$ \\
\hline Brown Swiss & $-0.019{ }_{(-0.26 ; 0.23)}$ & $\mathbf{- 0 . 1 2 1}(-0.19 ;-0.05)$ & $-0.016_{(-0.19 ; 0.15)}$ \\
\hline Simmental & $-0.142_{(-0.50 ; 0.22)}$ & $-\mathbf{0 . 1 2 1}(-0.21 ;-0.04)$ & $-0.116_{(-0.32 ; 0.15)}$ \\
\hline
\end{tabular}

${ }^{1}$ Mean $=$ mean of the marginal posterior density of the trait; HPD95 = lower and upper bounds of the $95 \%$ highest posterior density region. Means are in bold when their HPD95 upper and lower bounds both have the same sign as the mean value.

\section{Genetic Analyses Between dMEO Herds}

Variance Components. Variance components and intraherd heritability for fertility traits in the 2 groups of herds (LL and HL) are reported in Table 5. Genetic, herd, permanent environment, and residual variances differed across the 2 dMEO clusters. Different dairy cattle production herds have peculiar characteristics that lead to heterogeneity of parameters and variance (Costa et al., 2000) and can be related to herd management (Brotherstone and Hill, 1986). Overall, additive genetic variances for interval fertility traits $(\mathrm{iCF}, \mathrm{iFC}$, DO, and CInt) were higher in LL than in HL herds for all breeds ( $\mathrm{HO}=\sim 28 \%$; $\mathrm{BS}=\sim 13 \% ; \mathrm{SM}=\sim 23 \%$ ), except for $\mathrm{iFC}$ in $\mathrm{BS}$, where the genetic variance was $\sim 11 \%$ higher in HL than in LL herds. The residual variance was also higher in LL than in HL herds for BS $(\sim 8 \%)$ and SM $(\sim 13 \%)$, whereas it was lower in LL than in HL herds for HO for all interval traits $(\sim 3 \%)$ except for iCF, which had similar values in both herds. Herd variances were higher in LL than in HL herds for all traits in BS $(\sim 24 \%)$ and $\mathrm{SM}(\sim 19 \%)$, whereas for $\mathrm{HO}$ they were higher in LL than HL for $\mathrm{iCF}$ and CInt $(\sim 8 \%)$, and higher in HL than in LL for iFC and
DO ( $\sim 30 \%)$. Regarding the permanent environment variance, no clear pattern across traits and breeds was observed (Table 5). These results suggest that for specialized breeds in the low production tiers, management strategies applied at the herd level could be more effective than those applied at the individual level. In contrast, for SM, a dual-purpose breed, the differences in herd variances were lower than the differences in permanent environment variances. These results suggest that for dual-purpose breeds in the low production tiers, management strategies applied at the individual level could be more effective than those applied at the herd level.

For categorical traits (CR and NR56), on the other hand, the genetic, herd, residual, and permanent environment variances exhibited different patterns according to the trait and breed.

For trait dMEO, variances were higher in the HL than in the LL herds in all 3 breeds. In particular, the genetic, herd, permanent environment, and residual variances for HO were, respectively, 44, 22, 46, and $32 \%$ higher in HL than in LL; those for BS were 33, 25, 33, and $34 \%$ higher in HL than in LL; and those for SM were $29,15,40$, and $26 \%$ higher in HL than in LL. The 
Martinez-Castillero et al.: FERTILITY, GENETIC RELATIONSHIPS, AND ENVIRONMENT

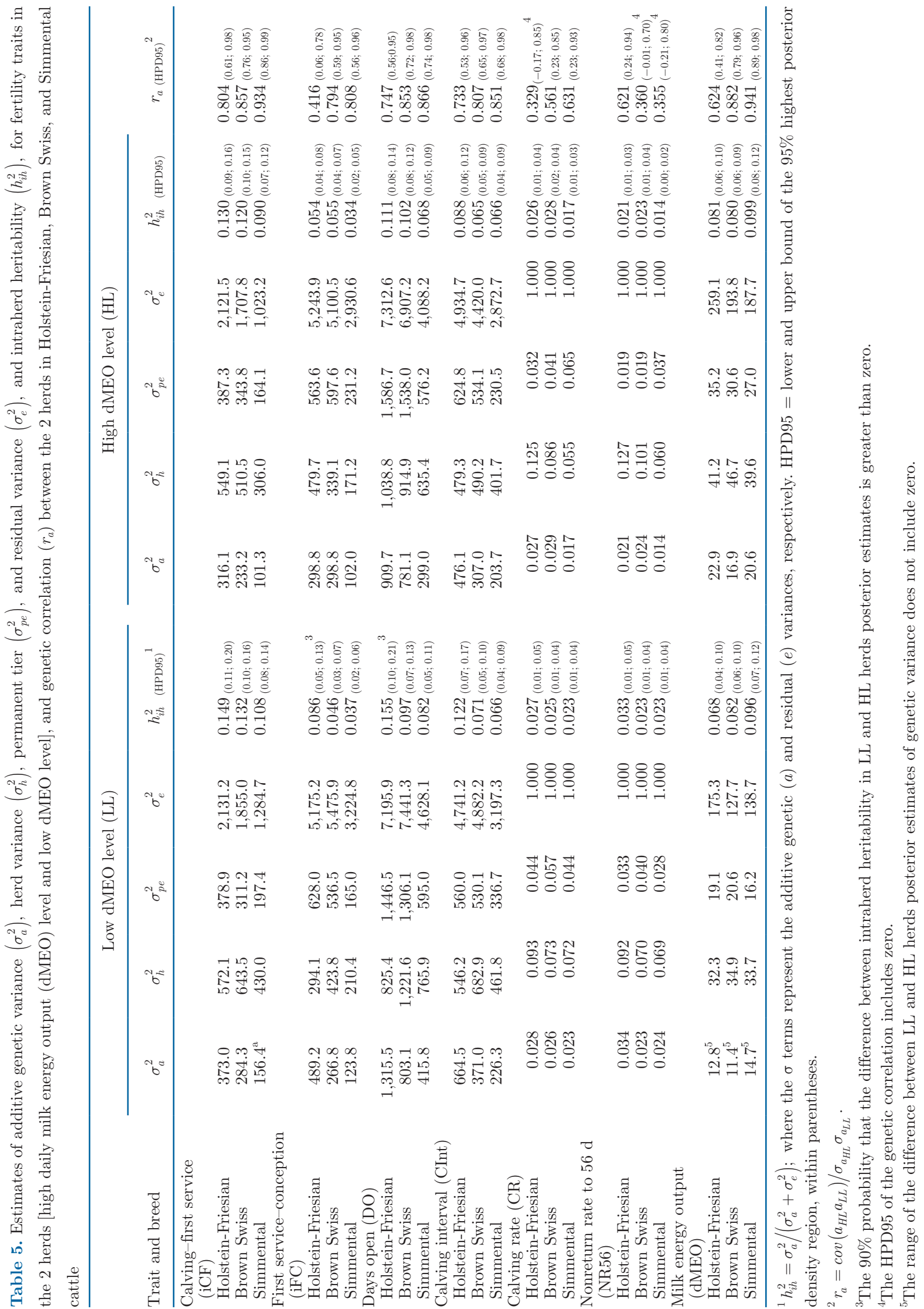


higher variances in the HL herd bring to light the difference between the 2 productivity herds, and validates the use of dMEO as a descriptor.

Intraherd Heritabilities. Overall, the estimates of intraherd heritability for interval fertility traits $(\mathrm{iCF}$, $\mathrm{iFC}, \mathrm{DO}$, and CInt) were higher in LL than in HL herds for $\mathrm{HO}(\sim 27 \%)$ and $\mathrm{SM}(\sim 14 \%)$, which can be mainly attributed to the larger genetic variance in LL herds. These findings agree with previous studies that reported a higher heritability of $\mathrm{iCF}$ at the low production level (Haile-Mariam et al., 2008; Strandberg et al., 2009; Ismael et al., 2016). However, for the trait CInt in $\mathrm{SM}$, heritabilities were homogeneous across the different production herds. In BS, the estimates of intraherd heritability of the traits $\mathrm{iCF}$ and CInt were higher in LL than in HL herds ( $9 \%)$, whereas those of the traits $\mathrm{iFC}$ and DO were higher in HL than in LL $(\sim 11 \%)$. For categorical traits (CR and NR56), the estimates of intraherd heritability were higher in LL than in HL herds for NR56 in HO ( 20\%), and for both CR and NR56 in SM $(\sim 33 \%)$. In BS, the estimates were higher in HL than in LL herds for trait CR $(\sim 11 \%)$, whereas for trait NR56, they were the same in the LL and HL herds. Furthermore, the estimates for dMEO were higher in HL than in LL herds in HO $(\sim 16 \%)$, and slightly higher in SM $(\sim 3 \%)$. In BS, on the other hand, the heritability estimates were slightly higher in LL than in HL herds $(\sim 2 \%)$. The differences in heritabilities were due to the variabilities in the genetic and residual variances between the different herds, in agreement with other studies (Berry et al., 2003; Boettcher et al., 2003; Nauta et al., 2006).

These results suggest that, depending on the trait and breed, herds with different production levels could achieve more or less genetic progress by using targeted selection of sires. For instance, HO and SM in LL herds could achieve a greater benefit from selection for interval fertility traits compared with $\mathrm{HO}$ and $\mathrm{SM}$ in $\mathrm{HL}$ herds (except for CInt in SM) when using the same top-ranking sires (or they can achieve the same benefit but using lower-ranking sires).

Genetic Correlations Between Divergent dMEO Herds. The genetic correlations between fertility traits expressed in the different dMEO herds are shown in Table 5. Among interval fertility traits (iCF, $\mathrm{iFC}, \mathrm{DO}$, and CInt), iCF showed the highest estimates, followed by DO, CInt, and finally iFC for all breeds. The genetic correlations for interval fertility traits (iCF, $\mathrm{iFC}, \mathrm{DO}$, and CInt) were weakest in $\mathrm{HO}$, ranging from $0.416(0.06-0.78)(\mathrm{iFC})$ to $0.804(0.61-0.98)(\mathrm{iCF})$, and strongest in SM, ranging from $0.808(0.56-0.96)$ (iFC) to $0.934(0.86-0.99)$ (iCF). The genetic correlations in BS ranged from $0.794(0.59-0.95)$ (iFC) to $0.857(0.76-$ 0.95) (iCF). In $\mathrm{HO}$, the genetic correlation for trait iFC was only moderately positive (0.416), but the estimates were characterized by large variability (HPD95 ranging from 0.06 to 0.78 ). The genetic correlations between herds were highly variable for categorical traits (CR and NR56) and were relevant only for trait CR in BS [0.561 (0.23-0.85)] and SM [0.631 (0.23-0.93)] , and for trait NR56 in HO [0.621 (0.24-0.94)]. Overall, the results obtained for these traits seemed to indicate the possibility of reranking of sires across the 2 different herd groups (especially for categorical traits and for $\mathrm{iFC}$ in HO). These estimates are in agreement with those obtained by Haile-Mariam et al. (2008) and by Strandberg et al. (2009), who found genetic correlations between different production herds of around 0.80 for the traits days to first service and CInt, and around 0.60 or lower for the trait NR56.

The genetic correlation between herds (Table 5) for dMEO was stronger in SM than in HO and BS, providing further support for the differences in robustness and environmental sensitivity between dual-purpose and specialized breeds (Bytyqi et al., 2007). Furthermore, the broader range of the HPD95 bounds, more noticeable for BS, suggests heterogeneity of variances across herds. Compared with HL herds, the LL herds could benefit from the use of sires with higher EBV to make genetic progress; that is, to shorten the mean value of the interval fertility traits and increase the incidence of the categorical traits.

\section{CONCLUSIONS}

In this study, we demonstrated that dMEO is a good descriptor to classify herds at different production levels for investigating reproductive performances in different dairy cattle breeds. Our results highlight that dual-purpose breeds are characterized by lower environmental sensitivity than specialized breeds. The differences in heritability across herds of different dMEO tiers suggest that herd or production level can affect reproductive performances in dairy cattle and possibly the selection process. Although genetic correlations between fertility traits in low and high dMEO herds showed large variability, results support using separate genetic evaluations of fertility in the different herdenergy strata.

\section{ACKNOWLEDGMENTS}

We thank the "Associazione Provinciale delle Organizzazioni Zootecniche Altoatesine/Vereinigung der Sudtiroler Tierzuchtverbande" of Bolzano/Bozen, Italy, for providing the data. The authors are also grateful to the Italian Holstein-Friesian and Jersey Cattle Breeders Association (ANAFIJ, Cremona, Italy), the Italian 
Brown Swiss Cattle Breeders (ANARB, Verona, Italy) and the Italian Simmental Cattle Breeders (ANAPRI, Udine, Italy) for providing pedigree information. The authors have not stated any conflicts of interest.

\section{REFERENCES}

Bello, N. M., J. S. Stevenson, and R. J. Tempelman. 2012. Invited review: Milk production and reproductive performance: Modern interdisciplinary insights into an enduring axiom. J. Dairy Sci. 95:5461-5475. https://doi.org/10.3168/jds.2012-5564.

Berry, D. P., F. Buckley, P. Dillon, R. D. Evans, M. Rath, and R. F. Veerkamp. 2003. Estimation of genotype x environment interactions, in a grass-based system, for milk yield, body condition score, and body weight using random regression models. Livest. Prod. Sci. 83:191-203. https://doi.org/10.1016/S0301-6226(03)00098-8.

Bittante, G., R. Negrini, M. Bergamaschi, A. Cecchinato, and H. Toledo-Alvarado. 2020. Pure-breeding with sexed semen and crossbreeding with semen of double-muscled sires to improve beef production from dairy herds: Factors affecting heifer and cow fertility and the sex ratio. J. Dairy Sci. https://doi.org/10.3168/jds.2019 -17932 .

Boettcher, P. J., J. Fatehi, and M. M. Schutz. 2003. Genotype $\times$ environment interactions in conventional versus pasture-based dairies in Canada. J. Dairy Sci. 86:383-389. https://doi.org/10.3168/jds .S0022-0302(03)73617-0.

Brotherstone, S., and W. G. Hill. 1986. Heterogeneity of variance amongst herds for milk production. Anim. Prod. 42:297-303. https://doi.org/10.1017/S0003356100018067.

Buaban, S., M. Duangjinda, M. Suzuki, Y. Masuda, J. Sanpote, and K. Kuchida. 2015. Short communication: Genetic analysis for fertility traits of heifers and cows from smallholder dairy farms in a tropical environment. J. Dairy Sci. 98:4990-4998. https://doi.org/ 10.3168/jds.2014-8866.

Buttazzoni, L., and I. L. Mao. 1989. Genetic parameters of estimated net energy efficiencies for milk production, maintenance, and body weight change in dairy cows. J. Dairy Sci. 72:671-677. https://doi .org/10.3168/jds.S0022-0302(89)79158-X.

Bytyqi, H., J. Ødegard, H. Mehmeti, M. Vegara, and G. Klemetsdal. 2007. Environmental sensitivity of milk production in extensive environments: A comparison of Simmental, Brown Swiss, and Tyrol Grey using random regression models. J. Dairy Sci. 90:3883-3888. https://doi.org/10.3168/jds.2006-303.

Carvalho, P. D., A. H. Souza, M. C. Amundson, K. S. Hackbart, M. J. Fuenzalida, M. M. Herlihy, H. Ayres, A. R. Dresch, L. M. Vieira, J. N. Guenther, R. R. Grummer, P. M. Fricke, R. D. Shaver, and M. C. Wiltbank. 2014. Relationships between fertility and postpartum changes in body condition and body weight in lactating dairy cows. J. Dairy Sci. 97:3666-3683. https://doi.org/10.3168/ jds.2013-7809.

Cecchinato, A., A. Albera, C. Cipolat-Gotet, A. Ferragina, and G. Bittante. 2015. Genetic parameters of cheese yield and curd nutrient recovery or whey loss traits predicted using Fourier-transform infrared spectroscopy of samples collected during milk recording on Holstein, Brown Swiss, and Simmental dairy cows. J. Dairy Sci. 98:4914-4927. https://doi.org/10.3168/jds.2014-8599.

Costa, C. N., R. W. Blake, E. J. Pollak, P. A. Oltenacu, R. L. Quaas, and S. R. Searle. 2000. Genetic analysis of Holstein cattle populations in Brazil and the United States. J. Dairy Sci. 83:2963-2974. https://doi.org/10.3168/jds.S0022-0302(00)75196-4.

de Vries, M. J., and R. F. Veerkamp. 2000. Energy balance of dairy cattle in relation to milk production variables and fertility. J. Dairy Sci. 83:62-69. https://doi.org/10.3168/jds.S0022-0302(00)74856-9.

Falconer, D. S. S. 1960. Introduction to Quantitative Genetics, first edition. Oliver and Boyd, Edinburgh, United Kingdom.

González-Recio, O., and R. Alenda. 2005. Genetic parameters for female fertility traits and a fertility index in Spanish dairy cattle. J. Dairy Sci. 88:3282-3289. https://doi.org/10.3168/jds.S0022 -0302(05)73011-3.
Gredler, B., and U. Schnyder. 2013. New genetic evaluation of fertility in Swiss Brown Swiss. Interbull Bull. 47:226-229.

Haile-Mariam, M., M. J. Carrick, and M. E. Goddard. 2008. Genotype by environment interaction for fertility, survival, and milk production traits in Australian dairy cattle. J. Dairy Sci. 91:4840-4853. https://doi.org/10.3168/jds.2008-1084.

Hansen, L. B., J. B. Cole, G. D. Marx, and A. J. Seykora. 1999. Productive life and reasons for disposal of Holstein cows selected for large versus small body size. J. Dairy Sci. 82:795-801. https://doi .org/10.3168/jds.S0022-0302(99)75298-7.

Hou, Y., P. Madsen, R. Labouriau, Y. Zhang, M. S. Lund, and G. Su. 2009. Genetic analysis of days from calving to first insemination and days open in Danish Holsteins using different models and censoring scenarios. J. Dairy Sci. 92:1229-1239. https://doi.org/10 $.3168 /$ jds.2008-1556.

Ismael, A., E. Strandberg, B. Berglund, M. Kargo, A. Fogh, and P. Løvendahl. 2016. Genotype by environment interaction for the interval from calving to first insemination with regard to calving month and geographic location in Holstein cows in Denmark and Sweden. J. Dairy Sci. 99:5498-5507. https://doi.org/10.3168/jds .2015-10820

Liu, Z., J. Jaitner, F. Reinhardt, E. Pasman, S. Rensing, and R. Reents. 2008. Genetic evaluation of fertility traits of dairy cattle using a multiple-trait animal model. J. Dairy Sci. 91:4333-4343. https://doi.org/10.3168/jds.2008-1029.

Miglior, F., A. Fleming, F. Malchiodi, L. F. Brito, P. Martin, and C. F. Baes. 2017. A 100-Year Review: Identification and genetic selection of economically important traits in dairy cattle. J. Dairy Sci. 100:10251-10271. https://doi.org/10.3168/jds.2017-12968.

Muuttoranta, K., A.-M. Tyrisevä, E. A. Mäntysaari, J. Pösö, G. P. Aamand, and M. H. Lidauer. 2019. Genetic parameters for female fertility in Nordic Holstein and Red Cattle dairy breeds. J. Dairy Sci. 102:8184-8196. https://doi.org/10.3168/jds.2018-15858.

Nauta, W. J., R. F. Veerkamp, E. W. Brascamp, and H. Bovenhuis. 2006. Genotype by environment interaction for milk production traits between organic and conventional dairy cattle production in The Netherlands. J. Dairy Sci. 89:2729-2737. https://doi.org/10 .3168/jds.S0022-0302(06)72349-9.

NRC. 2001. Nutrient Requirements of Dairy Cattle. 7th rev. ed. National Research Council, Washington, DC.

Patton, J., D. A. Kenny, S. McNamara, J. F. Mee, F. P. O'Mara, M. G. Diskin, and J. J. Murphy. 2007. Relationships among milk production, energy balance, plasma analytes, and reproduction in Holstein-Friesian cows. J. Dairy Sci. 90:649-658. https://doi.org/ 10.3168/jds.S0022-0302(07)71547-3.

Philipsson, J., and B. Lindhé. 2003. Experiences of including reproduction and health traits in Scandinavian dairy cattle breeding programmes. Livest. Prod. Sci. 83:99-112. https://doi.org/10.1016/ S0301-6226(03)00047-2.

Piccand, V., E. Cutullic, S. Meier, F. Schori, P. L. Kunz, J. R. Roche, and P. Thomet. 2013. Production and reproduction of Fleckvieh, Brown Swiss, and 2 strains of Holstein-Friesian cows in a pasturebased, seasonal-calving dairy system. J. Dairy Sci. 96:5352-5363. https://doi.org/10.3168/jds.2012-6444.

Poulsen, N. A., A. J. Buitenhuis, and L. B. Larsen. 2015. Phenotypic and genetic associations of milk traits with milk coagulation properties. J. Dairy Sci. 98:2079-2087. https://doi.org/10.3168/ jds.2014-7944

Pryce, J. E., M. D. Royal, P. C. Garnsworthy, and I. L. Mao. 2004. Fertility in the high-producing dairy cow. Livest. Prod. Sci. 86:125-135. https://doi.org/10.1016/S0301-6226(03)00145-3.

R Core Team. 2018. R: The R Project for Statistical Computing. https://www.r-project.org/.

Roche, J. R., N. C. Friggens, J. K. Kay, M. W. Fisher, K. J. Stafford, and D. P. Berry. 2009. Body condition score and its association with dairy cow productivity, health, and welfare. J. Dairy Sci. 92:5769-5801. https://doi.org/10.3168/jds.2009-2431.

Schlichtig, C. D., and M. Pigliucci. 1998. Phenotypic Evolution: A Reaction Norm Perspective. Sinauer Associates Inc., Sunderland, MA. 
Stocco, G., C. Cipolat-Gotet, T. Bobbo, A. Cecchinato, and G. Bittante. 2017. Breed of cow and herd productivity affect milk composition and modeling of coagulation, curd firming, and syneresis. J. Dairy Sci. 100:129-145. https://doi.org/10.3168/jds.2016-11662.

Strandberg, E., S. Brotherstone, E. Wall, and M. P. Coffey. 2009. Genotype by environment interaction for first-lactation female fertility traits in UK dairy cattle. J. Dairy Sci. 92:3437-3446. https:/ /doi.org/10.3168/jds.2008-1844.

Tenghe, A. M. M., A. C. Bouwman, B. Berglund, E. Strandberg, J. Y. Blom, and R. F. Veerkamp. 2015. Estimating genetic parameters for fertility in dairy cows from in-line milk progesterone profiles. J. Dairy Sci. 98:5763-5773. https://doi.org/10.3168/jds.2014-8732.

Tiezzi, F., C. Maltecca, A. Cecchinato, M. Penasa, and G. Bittante. 2012. Genetic parameters for fertility of dairy heifers and cows at different parities and relationships with production traits in first lactation. J. Dairy Sci. 95:7355-7362. https://doi.org/10.3168/jds .2012-5775

Tiezzi, F., C. Maltecca, M. Penasa, A. Cecchinato, Y. M. Chang, and G. Bittante. 2011. Genetic analysis of fertility in the Italian Brown Swiss population using different models and trait definitions. J. Dairy Sci. 94:6162-6172. https://doi.org/10.3168/jds.2011-4661.
Toledo-Alvarado, H., A. Cecchinato, and G. Bittante. 2017. Fertility traits of Holstein, Brown Swiss, Simmental, and Alpine Grey cows are differently affected by herd productivity and milk yield of individual cows. J. Dairy Sci. 100:8220-8231. https://doi.org/10 .3168/jds.2016-12442.

Weigel, K. A., P. M. VanRaden, H. D. Norman, and H. Grosu. 2017. A 100-Year Review: Methods and impact of genetic selection in dairy cattle-From daughter-dam comparisons to deep learning algorithms. J. Dairy Sci. 100:10234-10250. https://doi.org/10.3168/ jds.2017-12954.

Windig, J. J., M. P. L. Calus, and R. F. Veerkamp. 2005. Influence of herd environment on health and fertility and their relationship with milk production. J. Dairy Sci. 88:335-347. https://doi.org/10 .3168/jds.S0022-0302(05)72693-X.

Yang, H., and G. Su. 2016. Impact of phenotypic information of previous generations and depth of pedigree on estimates of genetic parameters and breeding values. Livest. Sci. 187:61-67. https:// doi.org/10.1016/j.livsci.2016.03.001. 